\title{
An important cardiac surgery milestone: The first known stopped-heart operation
}

\author{
Lars G. Svensson, MD, PhD, and Tomislav Mihaljevic, MD, Cleveland, Ohio
}

\footnotetext{
From the Heart, Vascular, and Thoracic Institute, Cleveland Clinic, Cleveland, Ohio. Disclosures: The authors reported no conflicts of interest.

The Journal policy requires editors and reviewers to disclose conflicts of interest and to decline handling or reviewing manuscripts for which they may have a conflict of interest. The editors and reviewers of this article have no conflicts of interest.

Received for publication June 23, 2021; accepted for publication Aug 16, 2021; available ahead of print Aug 21, 2021.

Address for reprints: Lars G. Svensson, MD, PhD, Department of Thoracic and Cardiovascular Surgery, Cleveland Clinic, 9500 Euclid Ave/J1-227, Cleveland, OH 44195 (E-mail: svenssl@ccf.org).

JTCVS Techniques 2021;10:460-3

2666-2507

Copyright $@ 2021$ The Author(s). Published by Elsevier Inc. on behalf of The American Association for Thoracic Surgery. This is an open access article under the CC BY-NC-ND license (http://creativecommons.org/licenses/bync-nd/4.0/).

https://doi.org/10.1016/j.xjtc.2021.08.025
}

$\checkmark$ Video clip is available online.

On May 6, 1953, John Gibbon, MD, performed the first heart operation using a heart-lung machine without stopping the heart ${ }^{1}$; afterward, various inflow occlusion types of operations continued to be performed, and C. Walton Lillehei was using cross-circulation for heart operations. ${ }^{2}$ Meanwhile, Melrose and his team were experimenting in the laboratory on inducing cardiac arrest with potassium. ${ }^{3}$ On February 17, 1956, Donald Effler, MD, and Larry Groves, MD, ${ }^{4}$ performed the first documented operation in which the heart was stopped with aortic occlusion and potassium citrate infusion on a cardiopulmonary bypass pump (built by Willem Kolff, MD) with a 17-minute pump time. There is no indication from the report of the first 3 operations done with potassium arrest of the heart on cardiopulmonary bypass. In addition, there is no record of Effler and Groves previously doing ventricular septal defect (VSD) closures with either cross-circulation or cardiopulmonary bypass without stopping the heart.

\section{CASE REPORT}

The patient (who signed HIPAA [Health Insurance Portability and Accountability Act of 1996] forms and provided written consent to share his story and medical information with media, since institutional review board approval was not needed) was a 17-month-old child weighing 17 pounds when he underwent surgery. He suffered from failure to thrive, could not sleep lying flat, and had repeated episodes surgery.

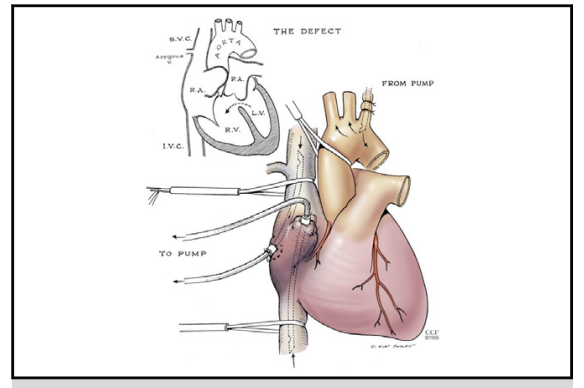

Colored illustrations of the original drawings of the first cardioplegic arrest operation.

CENTRAL MESSAGE

The first known stopped-heart operation, performed by Donald Effler, MD, and Larry Groves, MD, was a precursor to what has become a major contribution to cardiovascular care of patients.

See Commentaries on pages 464 and 466.

of pulmonary edema and "pneumonia." His parents had to pace with him at night to try to get him to sleep. F. Mason Sones, MD, who would perform the first coronary angiogram on October 30,1958, performed a cardiac catheterization and documented a high VSD and pulmonary hypertension. The patient's record notes that Dr Sones informed the parents of Dr Effler's research on using the heart-lung machine to close heart defects, as well as Dr Effler's caution that the operation carried a $25 \%$ to $30 \%$ risk of death. The patient's family agreed to proceed, and the referring doctor was invited to observe. Dr Sones ordered "fresh whole blood" and to "start him on antibiotic" before

The operation report describes, "A transverse anterior thoracotomy incision was made through the right $4^{\text {th }}$ interspace, the sternum was transected, and it was carried up the left $3^{\text {rd }}$ anterior interspace. After exposure was obtained, the left subclavian was isolated, and it was ligated immediately proximal to its primary division and divided after securing the base with a Pott's ductus clamp. An aortic cannula was then inserted and tied into the vessel; the tip of the cannula extended into the arch of the aorta" (reference Figure E1, $C$ and $D$, for images of typed operative notes, 
as well as handwritten notes from Dr Sones [Figure E1, $A$ ]). Dr Effler noted during surgery that the pulmonary artery was significantly enlarged, under high pressure, and more anterior in the chest. A trans-right ventricular approach was used to close the VSD that was "about the size of a 5 -cent piece which is a considerable defect for a heart of this size" with 4 interrupted silk sutures. After reperfusing the heart, spontaneous sinus rhythm returned. A lung biopsy was taken after weaning; otherwise, closure was uneventful. The patient's postoperative period was normal other than a fever of $103^{\circ} \mathrm{F}$, perhaps due to aspiration that was relieved with suction, but he was discharged shortly thereafter. The patient was asked to return 6 weeks postoperatively, and the patient's doctor wrote to Dr. Sones to report on the patient's remarkable recovery (Figure E1, $B$ ).

\section{DISCUSSION}

Time magazine ${ }^{5}$ and Reader's Digest reported on the remarkable operation. Today, the patient is a 66-year-old retired trumpeter who was inspired by the great band leader Doc Severinsen. He decided to study music because Dr Sones did not think it was safe for him to play sports after having 2 ribs removed. The patient is also a grandfather and has never experienced any other cardiovascular events. In 1980, Dr Effler wrote to the patient, saying that the patient's lucky number must be $17: 17^{\text {th }}$ day operation, 17 months, 17 pounds, and 17-minute pump time.

This seminal patient with potassium-induced arrest and cardioplegia on a pump was a precursor to what has become a major contribution to the cardiovascular care of patients. The 3 illustrations accompanying this case report (in
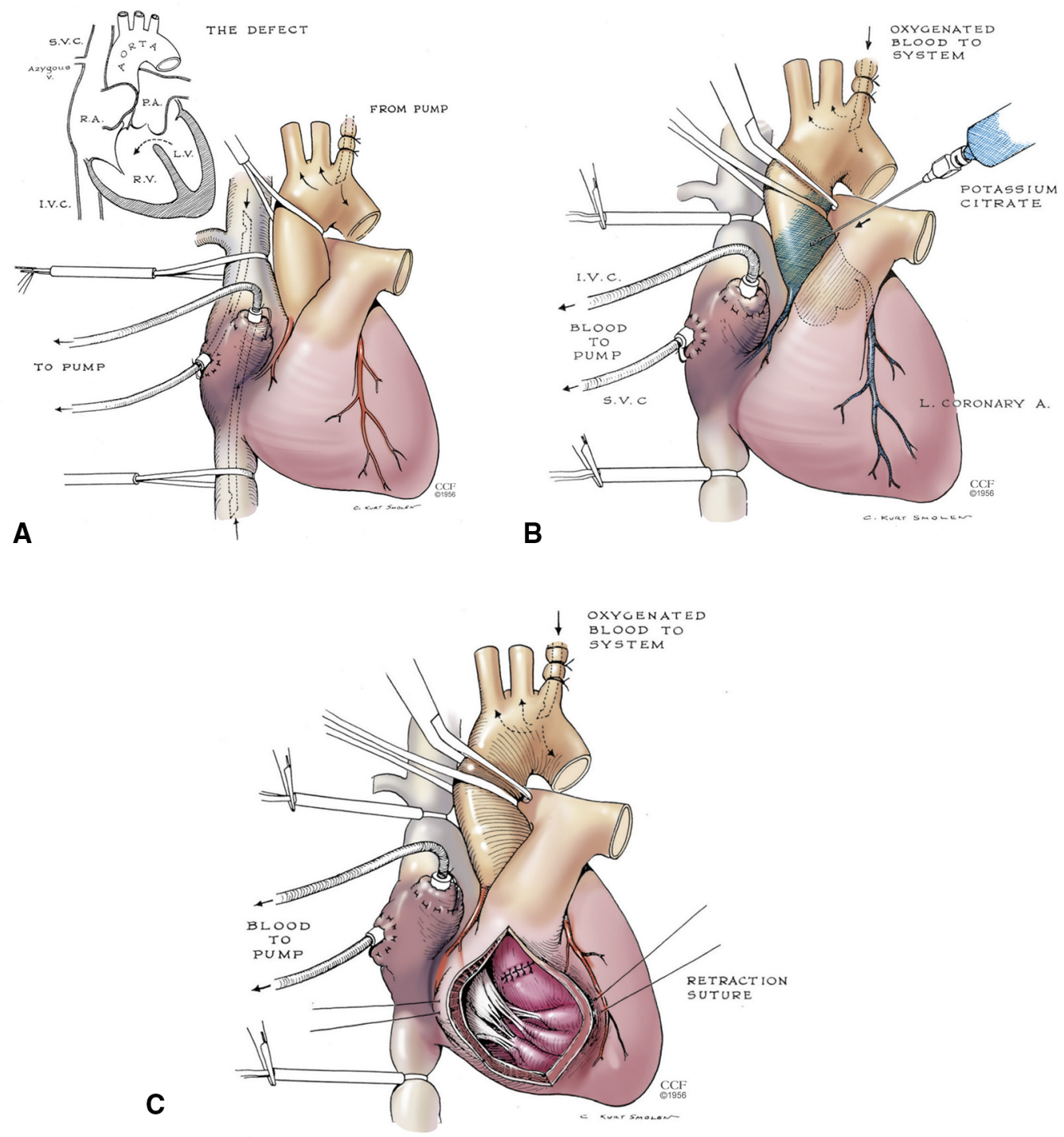

FIGURE 1. Colored illustrations of the original drawings of the first cardioplegic arrest operation. A, Illustration of the ventricular septal defect and cannulation via the left subclavian artery for cardiopulmonary bypass and venous drainage. B, Illustration of injection of potassium solution with the aorta crossclamped. C, Right ventriculotomy and closed ventricular septal defect. All images are reproduced with permission from Effler and colleagues. ${ }^{4}$ Copyright 2021 The Cleveland Clinic Foundation. All rights reserved. 


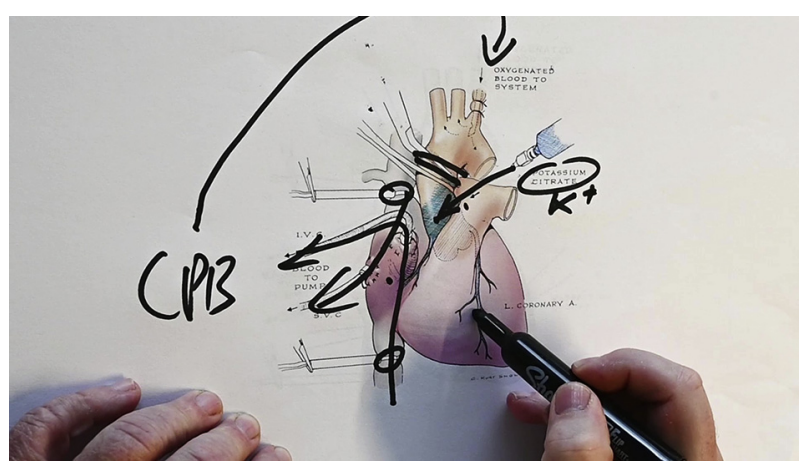

VIDEO 1. Case Report. Lars G. Svensson, MD, PhD, discusses the milestone first stopped-heart operation to examine its significance for the evolution of heart surgery procedures. Video available at: https://www.jtcvs. org/article/S2666-2507(21)00584-8/fulltext.

Figure 1) depict colorized versions of C. Kurt Smolen's original work. ${ }^{4}$ Additional explanation about this milestone operation appears in Video 1.
Currently, about 500,000 heart operations are done annually in the United States-most still induced with potassium cardioplegia. ${ }^{6}$ This patient's story reminds us that the pioneers of cardiac surgery were great heroes for attempting operations with unknown outcomes. Thanks to their groundbreaking efforts, most heart operations have less than a $1 \%$ risk of death.

\section{References}

1. Gibbon JH. The development of the heart-lung apparatus. Am J Surg. 1978;135: 608-19.

2. Warden HE, Cohen M, Read RC, Lillehei CW. Controlled cross circulation for open intracardiac surgery; physiologic studies and results of creation and closure of ventricular septal defects. J Thorac Surg. 1954;28:331-43.

3. Melrose DB, Dreyer B, Bentall HH, Baker JBE. Elective cardiac arrest. Lancet. $1955 ; 2: 21-2$.

4. Effler DB, Groves LK, Sones FM, Kolff WJ. Elective cardiac arrest in open-heart surgery; Report of three cases. Cleve Clin Q. 1956;23:105-14.

5. TIME [Internet], TIME USA; 2021. Medicine: surgery in the heart; April 30, 1956. Available at: http://content.time.com/time/subscriber/article/0,33009, 824204,00.html. Accessed May 21, 2021.

6. Dobson GP, Faggian G, Onorati F, Vinten-Johansen J. Hyperkalemic cardioplegia for adult and pediatric surgery: end of an era? Front Physiol. 2013;4:228. 

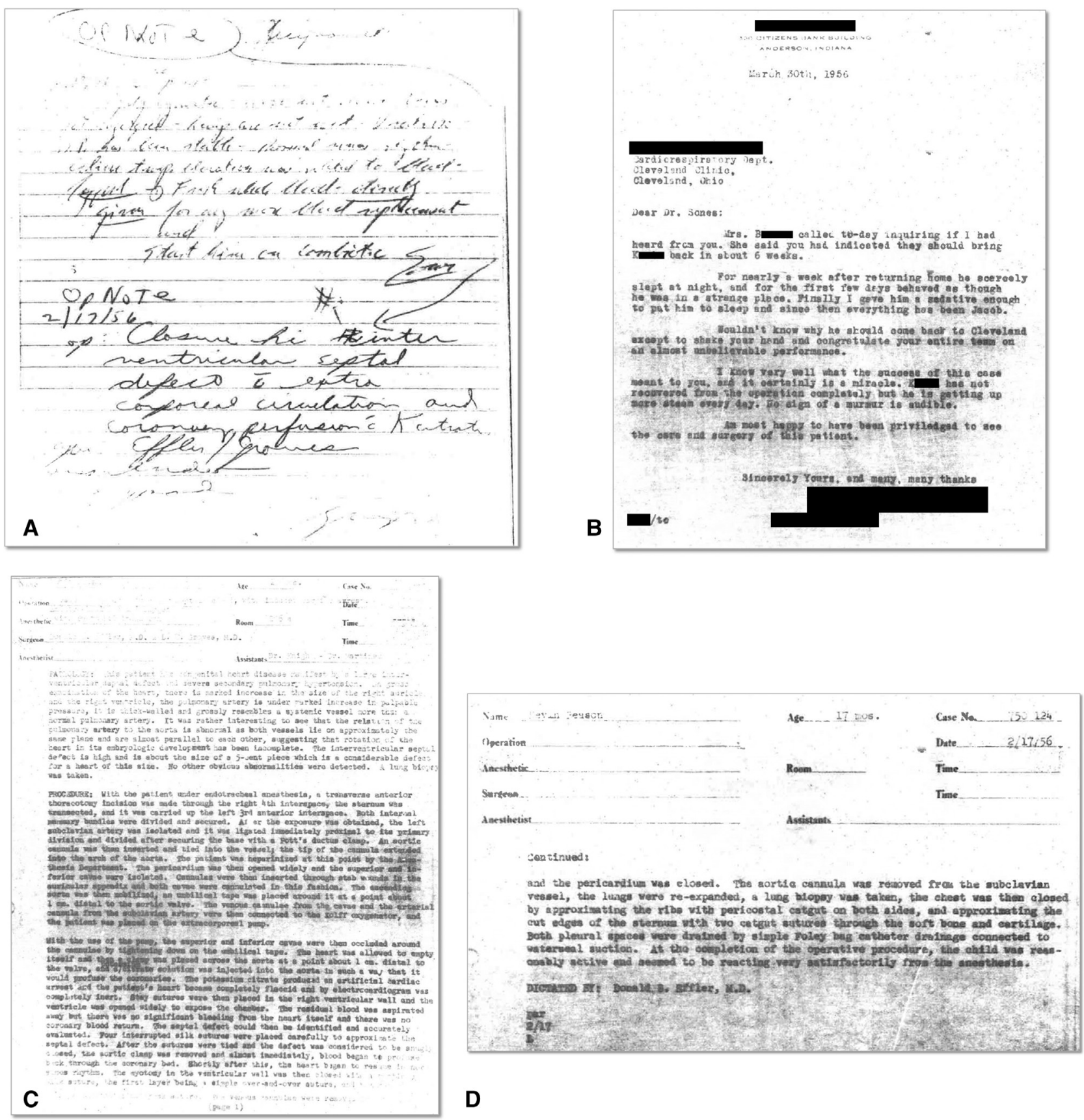

FIGURE E1. Original operative documents from first cardioplegic arrest operation. A, Handwritten operative notes with preprocedure instructions and notes about the procedure itself from Dr Sones. B, Letter written to Dr Sones from the patient's doctor with comments about the patient's recovery. $\mathrm{C}$ and D, Typed operative notes about the procedure. All images reproduced with the permission of the patient and Cleveland Clinic. 